Proc. Indian Acad. Sci. (Chem. Sci.), Vol. 105, No. 6, December 1993, pp. 591-601.

(C) Printed in India.

\title{
Applied photochemistry for free radical organic synthesis by means of distannane reagents
}

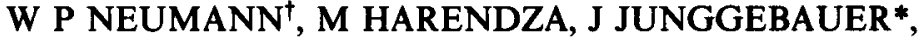 \\ $K$ LESSMANN and $H$ TEWS \\ Department of Chemistry, University of Dortmund, Otto-Hahn-Str. 6, D-4600 Dortmund \\ 50; Germany
}

\begin{abstract}
With optimized triplet sensitizers and longwave UV light $(300-350 \mathrm{~nm})$, distannanes $\mathbf{R}_{3} \mathrm{Sn}-\mathrm{SnR}_{\mathbf{3}}$, $\mathrm{R}$ being $\mathrm{Bu}$ by preference, are used as advantageous sources of stannyl radicals $\mathbf{R}_{3} \mathrm{Sn}$ that are versatile reagents for initiating organic free radical syntheses of many kinds. Elusive examples are presented. Thus, desired but slow radical steps like cyclizations, intermolecular additions or dimerization of the intermediate radicals can be preferentially carried out by using mild, adjusted, or no H-donors for terminating the radical reactions. In the second part, the development of a polystyrene-supported distannane is reported, where both tin atoms are covalently and firmly bound to the polymer. This reactive polymer is insoluble in common solvents. Its porous beads can be separated from the mixture after the reaction quantitatively and simply by filtration and regenerated for multiple use. The application of this new-type of photochemical source of stannyl radicals is demonstrated by typical examples. Its application offers both economical and ecological advantages of easier processing and of avoidance of organotin waste products, thus contributing to environmental protection.
\end{abstract}

Keywords. Free radical syntheses; stannyl radicals, distannanes, reactive polymers; polystyrene-supported distannane.

\section{Introduction}

In recent years, great interest in organic synthesis has been directed toward free radical reactions. Complicated molecular structures including biomolecules and products of pharmaceutical interest can be synthesized in very high yields by this method, often in multistep, one-pot reactions, which are called tandem or cascade reactions. Stannyl radicals play a major role as reagents in these syntheses that are very often of high or complete chemo-, regio-, stereo-, and enantioselectivity (Hoffmann 1992). A few additional, important statements should be cited:

"Within the last 15 years, an authentic explosion of synthetic applications of free radical reactions occurred; they have gained a remarkable position among the selective methods of synthesis." (Minisci 1989.)

The dramatic advances in the application of free radical reactions to problems in organic synthesis can be attributed in good measure to the versatility of trialkyltin hydride reagents." (Curran 1989.)

${ }^{*}$ For correspondence; ${ }^{\dagger}$ deceased 
"The reduction of organic functional groups by organotin hydrides ... has become the most commonly used method for the synthetic application of free radical carbon-carbon bond formation." (Curran 1988.)

For example, organotin hydrides, mostly $\mathrm{Bu}_{3} \mathrm{SnH}$ (Neumann 1987) are used for highly selective defunctionalizations of complicated, often multifunctional molecules (figure 1).

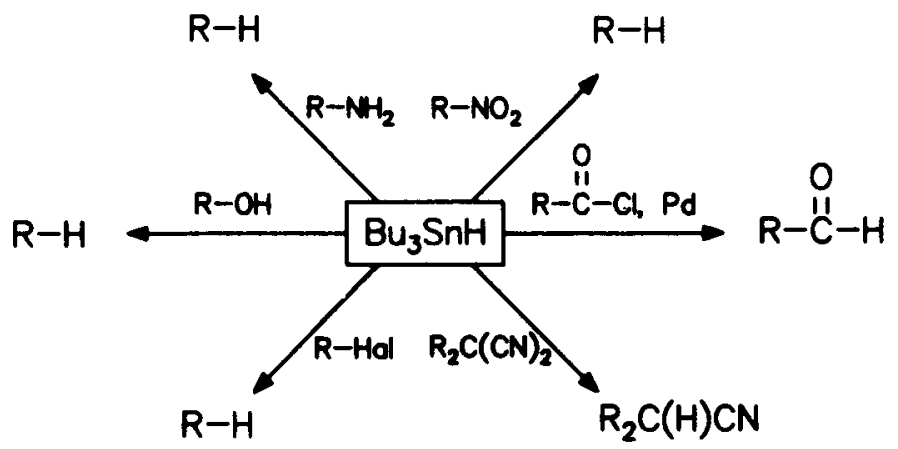

Figure 1. The versatility of trialkyltin hydrides in organic synthesis.

But, in all these cases, the generation of the reagent $\mathrm{R}_{3} \mathrm{Sn}^{\circ}$ is inherently coupled with the presence of $\mathrm{R}_{3} \mathrm{SnH}$ which is a very strong radical scavenger. This can be, in multistep reactions, a limiting drawback, since the desired, but relatively slow intermediate radical transformations like cyclizations cannot take place, or only proceed to an unsatisfactory extent, as explained by a few examples (scheme 1), selected out of the many described in the literature. In several cases, a syringe technique, i.e. very slow mechanical pumping (e.g. within $4 \mathrm{~h}$ ) of the $\mathrm{R}_{3} \mathrm{SnH}$ solution into the reaction mixture provided some improvement (Curran 1y88).<smiles>C=CCC1CC(=C)N1C(Cl)C(=O)OC(C)(C)C</smiles><smiles>CC(C)(C)OC(=O)[C@H]1CCCC2CC(=O)N21</smiles><smiles>C=CCC1CC(=O)N1CC(=O)OCc1ccccc1</smiles>

$\begin{array}{lrrr} & 0.02 M & 20 \% & 50 \% \\ \text { Bachi et al (1987) } & 0.003 \mathrm{M} & 50 \% & 5 \%\end{array}$<smiles>C=CCCCCCBr</smiles>

2-10 exs.

Walling and Cioffari (1972)
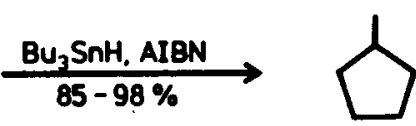

$5 \%$

Scheme 1. Examples of intermediate radical transformations.

Nevertheless, in most of these cases, a decoupling of the generation of stannyl radicals $\mathrm{R}_{\mathbf{3}} \mathrm{Sn}^{\circ}$ from the presence of the very strong radical scavenger $\mathrm{R}_{3} \mathrm{SnH}$ is desirable. Other sources of stannyl radicals are therefore to be sought for. 


\section{Distannanes $\mathbf{R}_{\mathbf{3}} \mathbf{S n}-\mathrm{SnR}_{\mathbf{3}}$ as sources for stannyl radicals}

Based on our experience with organotin compounds (Neumann 1970), we regarded distannanes as promising objects in our search for new $\mathrm{R}_{3} \mathrm{Sn}^{\prime}$ sources. With normal residues like $R=B u$, they are thermally very stable, generally up to $200^{\circ} \mathrm{C}$. Therefore, a photochemical splitting of their $\mathrm{Sn}-\mathrm{Sn}$ bond had to be envisaged.

\subsection{Direct photolysis of distannanes}

Direct photolysis needs shortwave UV light and gives, besides the desired Sn-Sn splitting, an unpleasant multitude of side and consecutive reactions, ending up with yellow or red polystannanes causing unwanted longwave absorptions, and also $\mathrm{R}_{4} \mathrm{Sn}$, elemental Sn, and so on (Lehnig et al 1978).

$$
\begin{aligned}
& \mathrm{R}_{3} \mathrm{Sn}-\mathrm{SnR}_{3} \stackrel{\mathrm{hv}}{\rightarrow}\left[\mathrm{R}_{3} \mathrm{Sn}-\mathrm{SnR}_{3}\right]^{\mathrm{T} \cdot \stackrel{k_{*}}{\rightarrow}} 2 \mathrm{R}_{3} \mathrm{Sn}^{\cdot}
\end{aligned}
$$

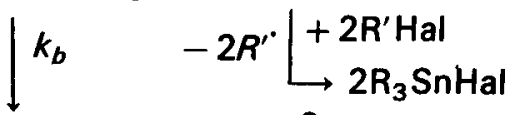

$$
\begin{aligned}
& \mathrm{R}=\mathrm{Me}: k_{a}>k_{b} ; \quad \mathrm{R}_{3} \mathrm{Sn}-\mathrm{SnR}_{2}+\mathrm{R}^{\cdot} \rightarrow \frac{2}{n}\left(\mathrm{R}_{2} \mathrm{Sn}\right)_{n}+\mathrm{R}-\mathrm{R} \text { etc. } \\
& \mathrm{R}=\mathrm{Et}: k_{a} \approx k_{b} \quad+\mathrm{R}_{6} \mathrm{Sn}_{2} \downarrow S_{\mathrm{H}} 2 \quad \mathrm{R}=\mathrm{Et}, \mathrm{Bu} \ldots \ldots \\
& \mathrm{R}_{\mathbf{4}} \mathrm{Sn}+\frac{1}{n}\left(\mathrm{R}_{\mathbf{2}} \mathrm{Sn}\right)_{n}, \quad \mathrm{R}=\mathrm{Me}
\end{aligned}
$$

Scheme 2. Photoreactions of $\mathrm{R}_{3} \mathrm{Sn}-\mathrm{SnR}_{3}$.

This older finding is of new inportance now: the $\lambda_{\max }$ of $236 \mathrm{~nm}$ corresponds to an energy taken up by the molecule of about $500 \mathrm{~kJ}$, what exceeds largely the dissociation energy of the Sn-Sn bond, the excess energy allowing unselective splitting of any bond in the molecule (figure 2). Even the use of the longer wavelength tailing occurring at higher concentrations, which are normal for preparative purposes, brought about very little progress in photochemical experiments.

\subsection{Triplet-sensitized photolysis of distannanes}

Therefore, a sensitized photolysis had to be envisaged. Since the degradation of $\mathrm{Bu}_{3} \mathrm{Sn}-\mathrm{SnBu}_{3}$ (hopefully the splitting of the $\mathrm{Sn}$-Sn bond) followed from a triplet state, as found by CIDNP experiments (Lehnig et al 1978), we tried empirically a number of triplet sensitizers (Harendza 1991; Tews 1991). A selection of these is given in table 1 . Whereas benzene and toluene had no or nearly no effect, diphenyl ether, acetone and $p$-methoxy acetophenone gave high yields of $\mathrm{R}_{3} \mathrm{Sn}^{\circ}$, as stated from the percentage of $\mathrm{R}_{3} \mathrm{SnBr}$ obtained, after admixing of alkyl halide scavengers for $\mathrm{R}_{3} \mathrm{Sn}^{\circ}$ like octyl bromide, by GLC analysis. Thus, an estimate of about $300 \mathrm{~kJ} / \mathrm{mol}$ for $E_{T}$ of $\mathrm{Bu}_{6} \mathrm{Sn}_{2}$ can be assumed, and benzene or toluene, e.g., can be used as photoinert solvents.

These sensitizers also protect, by their long wavelength absorption, the organic starting materials from direct photoactivation. This prevents undesired side reactions like photopolymerization of olefins. The usefulness of this new photochemical system should be checked now by a number of typical examples. 


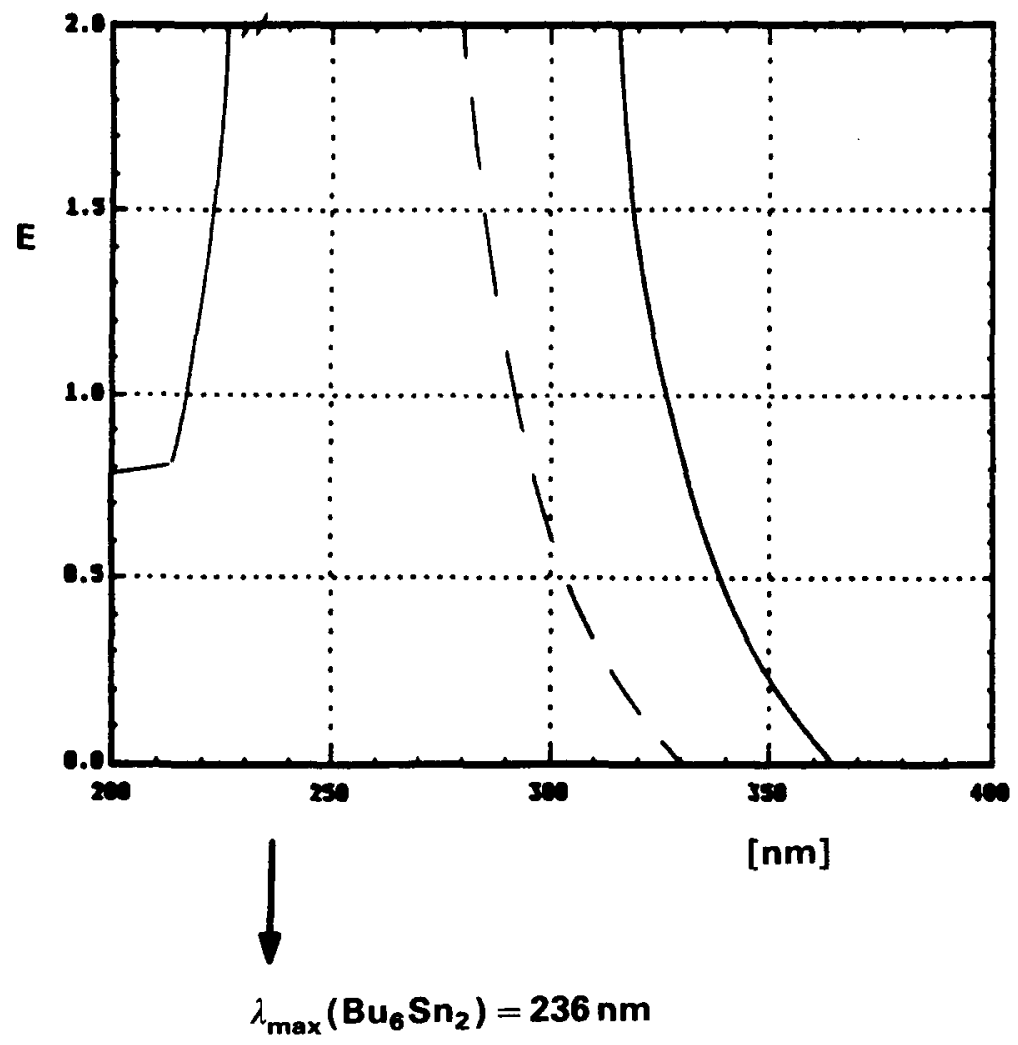

Figure 2. Photochemical application of the distannane $\mathrm{Bu}_{3} \mathrm{Sn}-\mathrm{SnBu}_{3}$ (LeBmann 1991). UV-Spectra of $\mathrm{Bu}_{6} \mathrm{Sn}_{2}(0.05 \mathrm{M})$. —- THF:tailing up to $352 \mathrm{~nm}$; --- $\mathrm{Me}_{2} \mathrm{CHOH}$ :tailing up to $330 \mathrm{~nm}$. $\lambda_{\max }\left(\mathrm{Bu}_{6} \mathrm{Sn}_{2}\right)=236 \mathrm{~nm} ; E\left(S_{0} \rightarrow S_{1}\right)=507 \mathrm{~kJ} / \mathrm{mol}$.

Table 1. Triplet energy and triplet lifetime of the used sensitizers.

\begin{tabular}{lcc}
\hline Sensitizer & $\begin{array}{c}\text { Triplet energy } \\
E_{T}[\mathrm{~kJ} / \mathrm{mol}]^{\mathrm{a}}\end{array}$ & $\begin{array}{c}\text { Triplet lifetime } \\
\tau_{T}[\mu \mathrm{s}](\mathrm{RT})^{\mathrm{a}}\end{array}$ \\
\hline Acetone & 300 & 6.3 \\
Diphenyl ether & $339^{\mathrm{b}}$ & $\sim 1^{\mathrm{b}}$ \\
p-MeO-acetophenone & 301 & 0.03 \\
Benzene & 352 & 8.0 \\
Toluene & 346 & 7.7 \\
\hline
\end{tabular}

Energy transfer: ${ }^{3} S^{*}+{ }^{1} Q \rightarrow{ }^{3} Q^{*}+{ }^{1} S$;

(Rule of thumb $\left.{ }^{\mathrm{c}}: E_{T}(S)-E_{T}(Q), 12-40 \mathrm{~kJ} / \mathrm{mol}\right)$;

$E_{T}\left(\mathrm{Bu}_{6} \mathrm{Sn}_{2}\right), 290-310 \mathrm{~kJ} / \mathrm{mol}$;

'Scaiano (1991); ' Engel and Monroe (1980); 'Becker (1984)

2.2a "Clean" generation of $\mathrm{R}_{3} \mathrm{Sn}$ " and its consequences: With $\mathrm{R}_{3} \mathrm{SnH}$, the $\alpha$-bromophenylacetic acid allyl ester gave, even under application of the syringe technique mentioned above, nothing other than the reduction product A (scheme 3) (Junggebauer 1992), unwanted in this case. This means, that even under these extreme conditions 


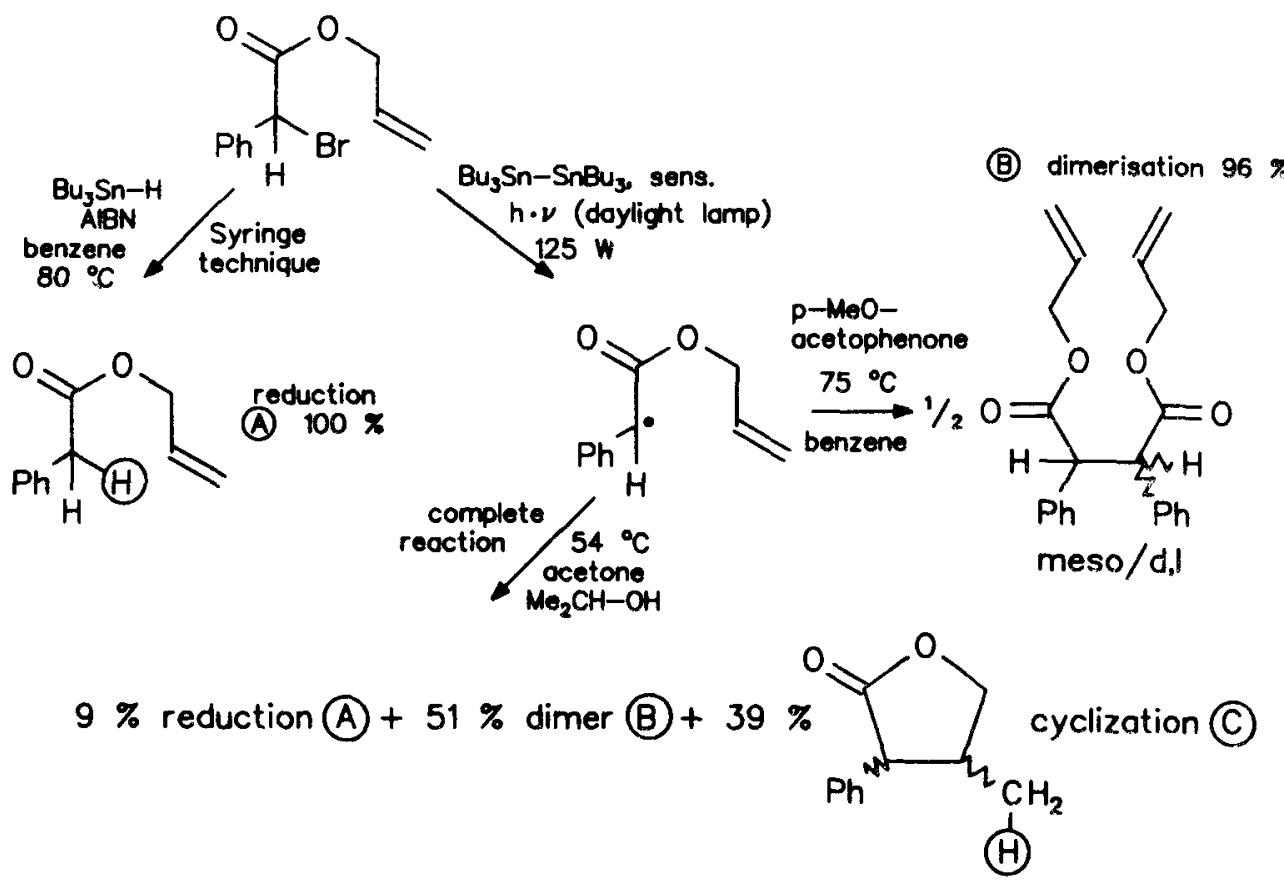

Scheme 3. Distannane for "clean" generation of stannyl radicals $\left(\mathrm{R}_{3} \mathrm{Sn}\right.$ ").

the intermediate radical, highly stabilized both by the phenyl and the carbonyl group, is scavenged very rapidly before anything else can happen.

But when we used our new triplet-sensitized distannane system and a $125 \mathrm{~W}$ daylight lamp, we obtained, surprisingly and exclusively, the dimer B (meso $/ d, l$ mixture) of the intermediate radical. $B$ is new, and may be of interest as a synthon because of its different functionalities.

With acetone and the $\mathrm{H}$-donor of intermediate strength (propanol-2) some $\mathrm{A}$ and $B$, as well as a new product $\mathbf{C}$ were identified. It indicates clearly an intermediate cyclization, i.e. addition to the isolated olefinic bond (which has to be a reversible one: an observation of importance for the fundamentals of free radical chemistry, whose discussion would exceed the scope of the present topic).

2.2b Further evidence for the governing role of the strength of the $H$-donor for product formation: The $\alpha$-bromoacetic acid styrylmethyl ester gives with $\mathrm{Bu}_{3} \mathrm{Sn}^{\circ}$ a radical, stabilized only by a carbonyl group. This is scavenged at $40^{\circ} \mathrm{C}$, before having time to react with anything else, even the medium $\mathrm{H}$-donor propanol-2, giving the reduction product $\mathrm{B}$. But at $75^{\circ} \mathrm{C}$, where the horseshoe-shaped conformation of the radical, enabling a cyclization, is more favoured, $90 \%$ scavenging of the cyclized radical-forming $B$ is found, when the weaker $\mathrm{H}$-donor toluene is applied (scheme 4).

The two latter examples demonstrate that a new degree of kinetic independence is gained by our system of decoupling the generation of $\mathrm{R}_{3} \mathrm{Sn}^{\circ}$ from any consecutive reactions.

2.2c Intermolecular radical additions: The addition of alkyl radicals to olefins such as acrylic derivatives (Giese 1985) is a kinetically tricky reaction. We selected it 
<smiles>CC(C)C(=O)OC/C=C/c1ccccc1</smiles>

$+9 \pi$

(B)

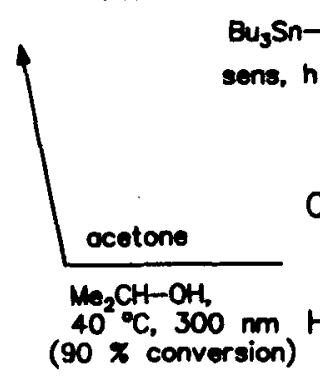

(A)<smiles>CC=CCOC(=O)CBr</smiles>

Ph<smiles>[CH2][C@H](O)[C@H]1COC(=O)C1</smiles>

Scheme 4. H-donor strength governs product formation.
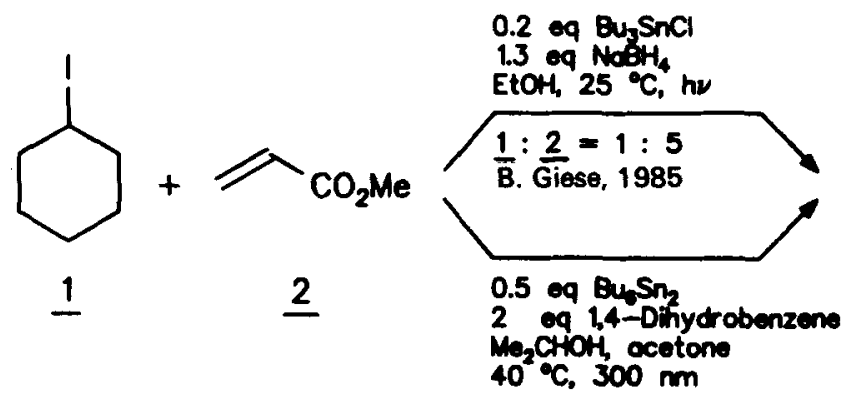<smiles>CC(=O)CCC1CCCCC1</smiles>

$\underline{1}: \underline{2}=1: 2$

Scheme 5. Synthetic application of on intermolecular addition.

as a further check for the synthetic application of our tin-mediated radical system (scheme 5). We could lower the excess of the acrylic compound, compared with that in the literature, from 5 to $2 \mathrm{~mol}$ per mol alkyl halide, thus also avoiding oligomer or polymer byproducts. With dihydrobenzene as $\mathrm{H}$-donor, we obtained the desired adduct as the only product.

\section{A polymer-supported distannane as photochemical source of stannyl radicals}

The advantages of stannyl radicals $\mathrm{R}_{3} \mathrm{Sn}^{*}$ in organic syntheses have clearly been demonstrated in the literature, and in the new results reported above. On the other hand, however, a problem caused by their use has also to be envisaged. In all cases, 
an equimolar amount of an organotin consecutive product $R_{3} \operatorname{SnX}$ arises, whatever $\mathrm{X}$ may be, and has to be cleanly separated from the desired reaction product.

"The drawback consists in the separation of these mostly toxic compounds and their consecutive products from the desired reaction products, which is mostly a difficult, and rarely a quantitative one. It might be, therefore, a meritorious research project to find new methods using such forms of organotin compounds which are easily to be separated." (Scheffold 1988.)

So we decided to engage ourselves with the synthesis of a polymer-supported distannane whose two tin atoms are both bound firmly to a polymer in a chemically stable position (figure 3 ). However, severe diffusion problems can arise by inherent motion of the excited sensitizer into the pores of the polymer, raising the question of sufficient lifetime of the triplet state.

We used our experience with polystyrene-supported organotin hydrides (Gerigk et al 1990; Neumann and Peterseim 1993), and started with the polystyrene-supported butyl tin chloride (scheme 6).

After several other attempts, Bogdanovic's magnesium (Bogdanovic et al 1984) was proved to be best suited for the distannane formation (Leßmann 1991). The capacity $(1.3 \mathrm{mmol} \mathrm{Sn}$ as $\mathrm{Sn}-\mathrm{Sn}$ per gram resin) is quite satisfying, some pending $\mathrm{Sn}-\mathrm{Cl}$ groups $(0.3 \mathrm{mmol} \mathrm{Sn}$ per gram resin) do not disturb the application. Their origin presumably is due to a lack of other $\mathrm{Sn}-\mathrm{Cl}$ groups in the vicinity within the same pore.

Of course, diffusion is a rate-limiting factor. Thus, we found, for example, in the central parts of larger beads of our macroporous polystyrene support, still high contents of unreacted $\mathrm{Sn}-\mathrm{Cl}$ groups, whereas in the outer parts the formation of $\mathrm{Sn}-\mathrm{Sn}$ groups by the $\mathrm{Mg}$ reagent is complete. This could be seen by $\mathrm{Sn}$ and $\mathrm{Cl}$ linescans through the surface of halved beads, using the electron microscope and the EXAFS method (Leßmann 1991).

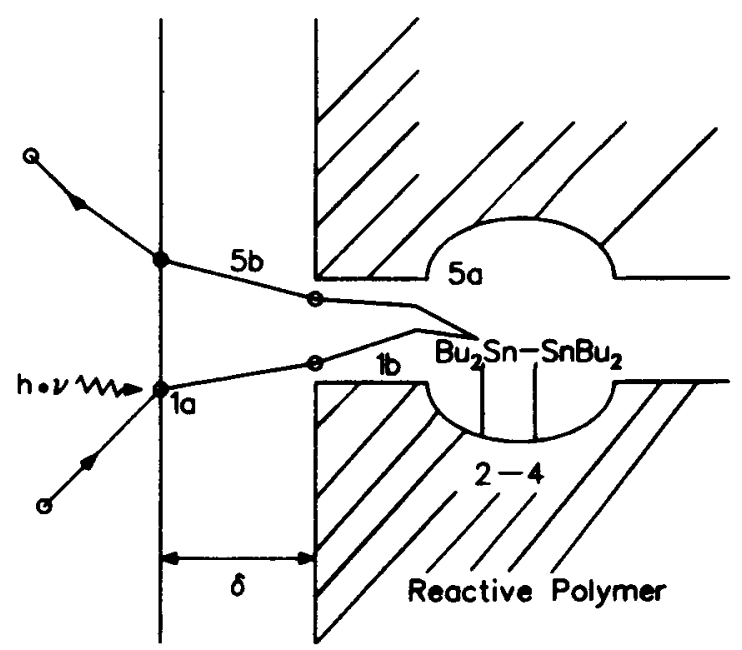

Figure 3. Principle of a Diffusion-Controlled Reaction at a Polymer-Supported Reagent (Simplified). $\delta$ Interface; 1a diffusion through the interface; $1 \mathrm{~b}$ diffusion in the pore; 2 adsorption; 3 reaction at the surface; 4 desorption; $5 \mathrm{a}$ diffusion in the pore; $5 \mathrm{~b}$ diffusion through the interface. Likewise, movements (two-dimensional ?), concentration of the other reactants and products. 


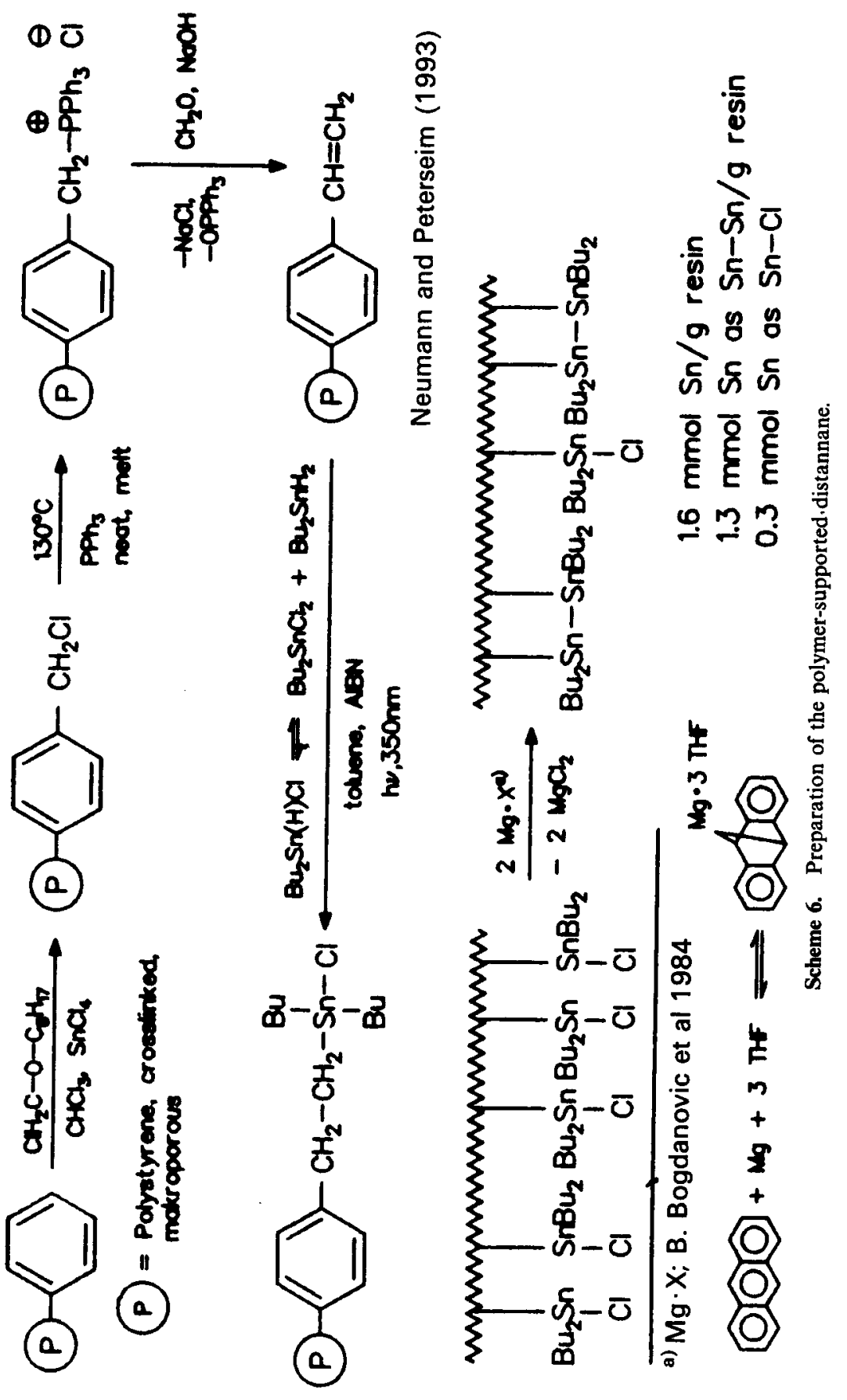




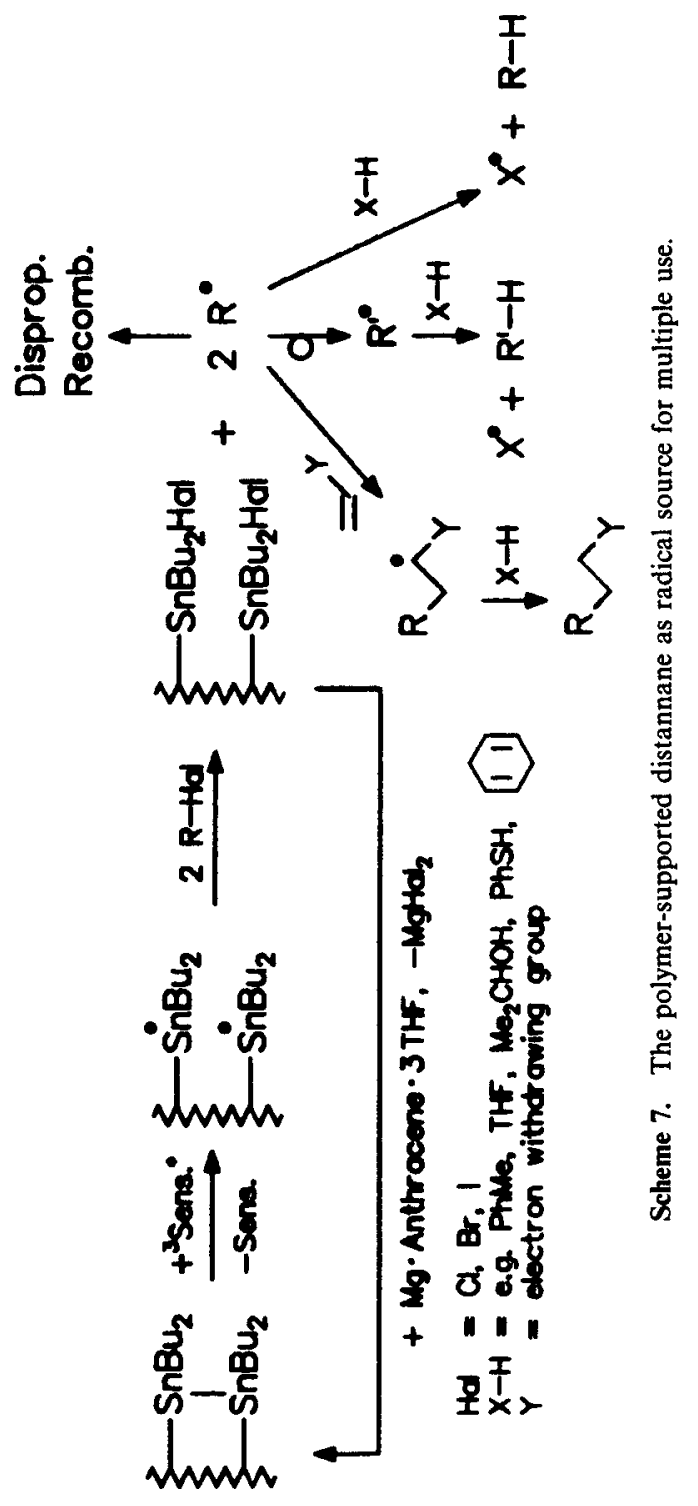



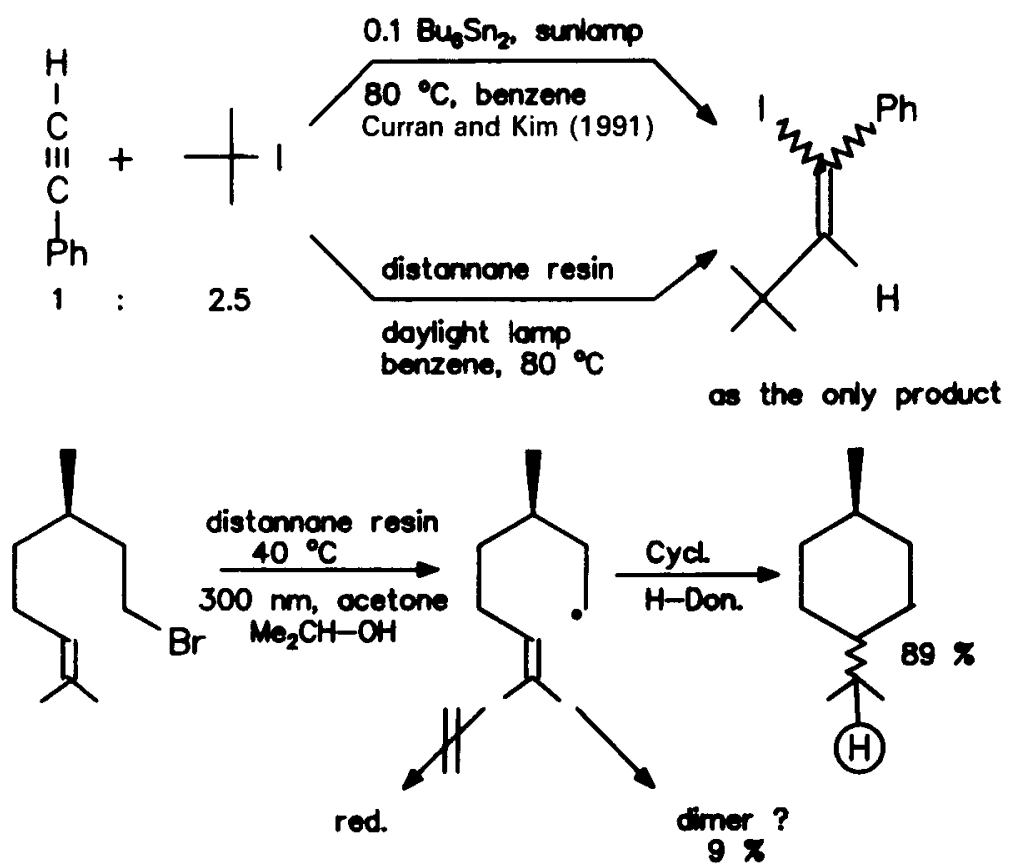

Scheme 8. Synthetic applications of the distannane resin.

Lastly, having gone through different exhausting series of experiments, the breakthrough has been achieved. The new reactive polymer can be used for the basic entrance reactions into free radical synthesis (scheme 7).

It works better than expected from theoretical points of view: rapid diffusion processes, perhaps of two-dimensional kinds in the pores, and a long-lived triplet-state of the immobilized distannane may be anticipated. Manifestation of the kinetics and the theoretical background needs further investigation.

Separation by filtering off, and regeneration of the reagent for multiple use, as shown above, is achieved without any problem.

Finally, two sophisticated examples should demonstrate the synthetic application of the new polystyrene-supported distannane (scheme 8).

\section{Conclusion}

This new, photochemical generation of stannyl radicals from distannanes opens up a broad variety of possibilities for interesting free-radical reactions useful in organic syntheses, hopefully also for molecules of biological, pharmaceutical or other importance. And, one day, our "daylight lamp", maybe, will be replaced by real daylight of the same wavelength (perhaps by means of a collector), i.e., by the source of daylight, the sun itself.

\section{Acknowledgements}

The work has been supported by the Volkswagen Foundation, the Fonds der Chemischen Industrie, and the Bayer AG. 


\section{References}

Bachi M D, DeMesmaeker A and Stevenart-DeMesmaeker N 1987 Tetrahedron Lett. 282637

Becker H G O 1984 Eine Einführung in die Photochemie (Stuttgart: Thieme Verlag)

Bogdanović B, Liao S, Mynott R, Schlichte K and Westeppe U 1984 Chem. Ber. 1171378

Curran D P 1988 Synthesis 417

Curran D P 1989 in Free radicals in synthesis and biology (ed.) F Minisci (London: Kluwer) p. 37

Curran D P and Kim D 1991 Tetrahedron 326171

Engel P S and Monroe B M 1980 Advances in photochemistry (eds) W A Noyes, G S Hammond and J N Pitts (New York: Interscience) vol. 4

Gerigk U, Gerlach M, Neumann W P, Vieler R and Weintritt V 1990 Synthesis 448

Giese B 1985 Angew. Chem., Int. Ed. Engl. 24553

Harendza M 1991 Photochemical generation of stannyl radicals, diploma thesis, University of Dortmund Hoffmann H M R 1992a Angew. Chem. 1041361

Hoffmann H M R 1992b Angew. Chem., Int. Ed. Engl. 31 910, and references therein

Junggebauer J 1992 Photochemical syntheses with distannane, Dr. rer. nat. Thesis, University of Dortmund, (in preparation)

Lehnig M, Neumann W P and Seifert P 1978 J. Organomet. Chem. 162145

LeBmann K 1991 New sources of stannyl radicals, Dr. rer. nat. Thesis, University of Dortmund

Minisci F (ed.) 1989 Free radicals in synthesis and biology (London: Kluver) p. xi

Neumann W P 1987 Synthesis 665

Neumann W P 1970 The organic chemistry of tin (New York: Wiley)

Neumann W P and Peterseim M 1993 Reactive polymers (submitted)

Scaiano J C (ed.) CRC handbook of organic photochemistry (Boca Raton, FL: CRC-Press)

Scheffold R 1988 Nachr. Chem. Tech. Lab. 36261

Tews H 1991 Triplet-sensitized photolysis of distannanes, Diploma thesis, University of Dortmund

Walling Ch and Cioffari A 1972 J. Am. Chem. Soc. 946059 